\title{
Adaptation to climate change in rainfed agriculture in the global South: Soil biodiversity as natural insurance ${ }^{1}$
}

\author{
Yoro Sidibé, ${ }^{a}$, Sébastien Foudi, ${ }^{b, *}{ }^{*}$ Unai Pascual ${ }^{b, c}$, Mette Termansen $^{\mathrm{d}}$
}

a) World Bank, Washington D.C., USA;

b) Basque Centre for Climate Change (BC3), 48940, Leioa, Spain;

c) Ikerbasque, Basque Foundation for Science, Bilbao 48013, Spain;

d) Department of Food and Resource Economics, Copenhagen University, Copenhagen, Denmark;

*) Corresponding author: sebastien.foudi@bc3research.org. Basque Centre for Climate Change (BC3), Scientific Campus of UPV/EHU; Sede Building 1; Barrio Sarriena, s/n 48940, Leioa, Spain.

\begin{abstract}
Increased drought frequency in many parts of the world, especially in the global South, is expected due to accelerating climate change. We present bioeconomic model aimed that unpacks the role of soil biodiversity as contributing to both increasing and stabilizing agricultural productivity in lowinput rainfed farming systems. The natural insurance value of soil biodiversity mostly depends on farmers' risk preferences as well as on the frequency of drought events to be insured against. We show that when the probability of drought increases, soil biodiversity conservation can be an optimal ecosystem-based adaptation strategy. However, this is only likely to be the case up to a given drought probability threshold. The natural insurance value of soil biodiversity for climate change adaptation in drought prone rainfed agricultural systems depends on a combination of key hydrological, agronomic and economic parameters.
\end{abstract}

Keywords: Ecosystem services, risk and uncertainty, climate change, adaptation, bioeconomic modelling

${ }^{1}$ Cite as: Sidibé Y., Foudi S., Pascual U., Termansen M. 2018. Adaptation to Climate Change in Rainfed Agriculture in the Global South: Soil Biodiversity as Natural Insurance. Ecological Economics. 146. 588-596. DOI (10.1016/j.ecolecon.2017.12.017). 


\section{Introduction}

In many parts of the global South, especially in sub-Saharan Africa (SSA), agricultural production is largely rainfed. Actually, $<5 \%$ of agricultural land in SSA is equipped for irrigation and large disparities are observed between countries (FAO, 2014). Rainfed agriculture in SSA is specially exposed to climate variability (Niang and Ruppel, 2014). Decrease in annual rainfall coupled with more frequent drought episodes has been observed over the past 30 years (Funk et al., 2008; Williams and Funk, 2011) and climate variability is expected to increase significantly in the region (Cooper et al., 2008; Niang and Ruppel, 2014). In this climatic context, significant crop yield losses are likely to occur (Roudier et al., 2011), putting the most vulnerable small scale farmers' food security at risk (Challinor et al., 2007; Niang and Ruppel, 2014; Schmidhuber and Tubiello, 2007).

Infrastructural investments in 'blue water' (from lakes or rivers) for agricultural systems in SSA is limited for several reasons, including financial constraints for large scale expansion of irrigation schemes (Rogers et al., 2002) and associated high transaction costs (Kadigi et al., 2012; Rosegrant and Cline, 2003), increased concerns about the environmental impacts of irrigation (Smakhtin, 2002); and also, the limited access of farmers to markets. In this context, investments in 'green water', i.e. water from precipitation and made available to plants in the soil, could reduce the risk of dry spells and drought locally (Falkenmark and Rockström, 2008). This is an ecosystem based strategy to manage soil ecosystems to improve adaptation to increased rainfall variability (Bewket, 2007; Biazin et al., 2012; Rockström et al., 2010). However, agroecologically based practices such as those involved in conservation agriculture (Hobbs et al., 2008; Pittelkow et al., 2014) also imply some costs to farmers (Giller et al., 2009).

Agricultural biodiversity is a complex and integral component of conservation agriculture, supporting multiple ecosystem functions and intermediate ecosystem services essential for agricultural productivity (Brussaard, 1997; Tscharntke et al., 2012) and food security (Pascual et al., 2013, 2011). It has been suggested that ecosystems with higher levels of biodiversity tend to use biotic and abiotic resources more effectively than less diverse ones and are more productive 
and stable (Turnbull et al., 2013). In soils, soil biota is important for soil productivity (Barrios, 2007; Hector and Bagchi, 2007), have complex interactions with aboveground biodiversity (De Deyn and Van der Putten, 2005), and impact hydrological pathways (Bardgett et al., 2001) and biogeochemical processes in the nutrient cycle (Swift et al., 2004). For example, Spurgeon et al. (2013) found in a meta-analysis that the abundance and complexity of fungal and earthworms impact soil structure stability and water infiltration rates. Species interact in a complex way; where soil macro fauna and earthworms, in particular, transform organic matter and facilitates and accelerate its decomposition by bacteria and fungi (Nielsen et al., 2011). Beyond the idea of species richness, an important hypothesis in ecology is that species are functionally redundant, and thus as a species may be lost in a system, another can take its place in terms of providing the same function (Bengtsson, 1998) ${ }^{2}$. Nielsen et al. (2011) have examined the functional redundancy hypothesis of soil biodiversity for carbon cycling. They found that both community composition and species richness influence carbon cycling. The role of species diversity within functional groups is thus important in soil ecology. In our approach, we use a standard definition of soil biodiversity as "the variation of soil life, from genes to communities, and the ecological complexes of which they are part, that is from micro-habitats to landscapes" (Turbé et al., 2010).

The capacity of biodiversity to enhance the flow of ecosystem services and their stability has been conceptualized as the natural insurance value of biodiversity for risk averse users of ecosystem services (Baumgärtner, 2007); soil biodiversity thus confers to ecosystem users an insurance against the variability of income ${ }^{3}$. Identifying the productive and insurance values of soil biodiversity are seen as an important step to understand the role of soil biodiversity conservation in climate change adaptation (Pascual et al., 2015). The studies focusing explicitly on the role of biodiversity from a farmer's perspective have been mostly concerned with plant biodiversity, focused on crop productivity (Chavas and Falco, 2012) and income variability (Di Falco and

\footnotetext{
${ }^{2}$ Functional redundancy occurs if multiple species share a trait that enhances ecosystem functioning. The chance of adding a species with a trait not observed in the community becomes smaller as species richness increases.

${ }^{3}$ In this approach, the insurance value of soil biodiversity is measured as a change in the risk premium due to a marginal change of biodiversity.
} 
Chavas, 2008; Finger and Buchmann, 2015). To date studies focused on soil biodiversity from a farmer's perspective are theoretical contributions that analyze the notion of the value of agrobiodiversity at large (Baumgärtner and Quaas, 2010; Omer et al., 2010) or on the productive value of soil biota (Foudi, 2012). There is thus a scant literature that integrates economic considerations into the viability of soil ecosystem-based approaches for sustainable agricultural intensification or/and climate smart agriculture. Here we use a theoretical bioeconomic model to fill this gap.

The insurance value is highly dependent upon the ecosystem properties, economic context and the risk preferences of users, and can be subjected to non-linearities and threshold effects (Baumgärtner and Strunz, 2014). Soil biodiversity has mainly an indirect value, as it influences intermediate ecosystem services such as water regulation via soil functions on water cycling (Pascual et al., 2015). To analyze some potential thresholds under which soil biodiversity conservation can help to manage soil moisture and lead to potential increase and a stabilization of crop production, we make the (intermediate) soil hydro-ecosystem service explicit via a production function approach. The model is particularly suitable for studying vulnerable small-holder farming systems, such as those associated with rainfed agriculture in SSA. Our model captures basic ecological-economic links between soil biodiversity, hydrological processes and small-scale farm economy under climate variability proxied by changes in the quantity of expected rainfall. Under such climatic variability, the management of soil moisture via soil biodiversity is seen as a key approach, mediated by farmers' risk preferences ${ }^{4}$. The model contributes to the understanding of the risk reducing properties of soil biodiversity from a farmers' perspective and helps to determine economically optimal soil conservation strategies in agroecosystems that rely on rainfall and that are not capitalized except via human and natural capital, such as those used by millions of smallholders in the global South. It highlights under which social-ecological conditions soil biodiversity conservation is seen as natural insurance against of rainfall variability.

\footnotetext{
${ }^{4}$ The elicitation of risk aversion has a long history in agricultural economics (Antle, 1987; Just and Pope, 1979; Lence, 2009) and its impact on policy is an active discussion topic (Just and Peterson, 2010; Just, 2008; Just and Just, 2011).
} 
The next section presents the basic building blocks of the bioeconomic model and establishes how soil biodiversity influences the mean and variance of agricultural production. Section 3 determines the economic optimal conservation strategy of a representative risk averse small-scale farmer, typical of rainfed agriculture in SSA, with soil biodiversity being the main mechanism to regulate soil moisture. The next section focuses on the impact of increased drought frequency on the farmer's optimal strategy towards soil biodiversity conservation. Finally, the last section concludes and offers some additional insights to enrich the current policy discourse on climate smart agriculture.

\section{The bioeconomic model}

We consider a rainfed farming system, typical of most of SSA, where rainfall is the only source of water for agricultural production. We assume soil biodiversity to be a stock of natural capital (Brock et al., 2009) which enables the supply of intermediate water regulation services in terms of water accumulation potential and water storage capacity, which in turn supports food production as a final ecosystem service (Pascual et al., 2015) or regulate nature's contribution to people (NCP) (Pascual et al., 2017). We first describe the hydrological-agronomic submodel and then the economic submodel, as components of the bioeconomic model.

\subsection{The hydrological-agronomic model}

Given that the rainfall pattern is a central feature of rainfed agriculture, without loss of generality, we assume two stochastic rainfall periods or key rainfall events during a given agricultural season. For each event/period a low level of rainfall, denoted $\pi_{l}$ or a high level of rainfall, $\pi_{h}$, occurs with probability $\varphi_{l}$ and $\varphi_{h}=1-\varphi_{l}$, respectively. Rainfall is then assumed to be absorbed by the soil prior to be used by plants for transpiration.

Different soil organisms play complementary roles in determining the fundamental characteristics of the soil, soil structure and soil texture (Altieri, 1999). This partly determines the way water infiltrates into the soil and the way water is retained. For example, organisms such as earthworms affect soil permeability while smaller organisms tend to have a greater impact on soil porosity by gradually breaking down the soil components and therefore affecting the soil's capacity to 
withhold water (Edwards and Arancon, 2004; Gupta and Larson, 1979; Hudson, 1994). Following Allison (1973) and Bastardie et al. (2005), we therefore assume that the higher the diversity of soil organisms, the more likely it is that soil has a higher capacity to store water, as represented by equation (1):

$$
S_{c}=L \times\left[I_{b}\right]^{\mu}
$$

where $S_{c}$ is the soil's water storage capacity, $L$ is a proportionality coefficient, $I_{b}$ is the stock of soil biodiversity and $\mu$ is a parameter between 0 and 1 . Equation (1) also states that soil biodiversity

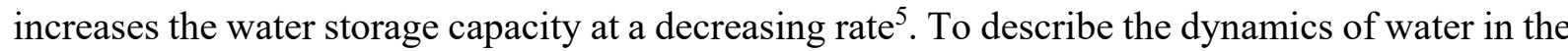
soil, we use a modified version of Darcy's law ${ }^{6}$ that describes the infiltration of water in a porous medium (Kirkham, 2005). The flow of water in the soil is described by a difference equation as a function of the total quantity of water in the porous medium and the intrinsic properties of the medium (Roscoe, 1968). Equation (2) adapts Darcy's law in a simple way:

$$
V_{t+1}-V_{t}=-\frac{k}{S_{c}} V_{t}
$$

where $V_{t}$ is the quantity of water in the soil at time $t$ and $k$ represents some intrinsic properties of the soil. Equation (2) states that a greater volume of water in the soil will lead to a proportionally greater water flow out of the soil. The water flows out of soil due to the gravitational force. The volume of water at $t+1$ is positively related to its storage capacity, Sc. Combined with equation (1) it implies that more biodiverse soils today retain more water for future use.

The total quantity of water available in the soil at any time is equal to the quantity previously available plus any new amount of water naturally brought by rainfall. When the quantity of water available is lower than the real evapotranspiration, the water becomes scarce, the plant is stressed, and withdraws the quantity of water available; when the water is not scarce $^{7}$, the plant's water

\footnotetext{
${ }^{5}$ The incremental species enhances soil storage capacity by different mechanisms but the possibility to bring additional water holding capacity is limited because of the intrinsic properties of the soil (Jhonson, 2009) and because of the functional redundancy of additional species.

${ }^{6}$ Darcy's law is a simplification of the more general Richard's law that represents water flow in non-saturated soils.

${ }^{7}$ In a setting of water scarcity, we assume that the plant is not affected by an excess of water such as during a flood event. Moreover, we assume that rainfall does not affect soil biodiversity.
} 
withdrawal corresponds to the evapotranspiration. That is, the amount of water used by plants is given by:

$$
X_{t}=\left\{\begin{array}{c}
E T_{t} \text { if } E T_{t} \leq V_{t-1}+\widetilde{\pi}_{t} \\
V_{t-1}+\widetilde{\pi}_{t} \text { if else }
\end{array}\right.
$$

where $X_{t}$ is the uptake of water by the plants at time $t$; ET is the rate of real evapotranspiration, and $V_{t-1}+\tilde{\pi}_{t}$ represents the total amount of water available in the soil, which is an additive function of the water remaining in the soil from period $t-1$ and the water that reaches the soil due to stochastic rainfall level $\tilde{\pi}_{t}$ at period $t$. Combining equations (2) and (3):

$$
V_{t}=\frac{V_{t-1}+\widetilde{\pi}_{t}-X_{t}}{(1+\beta)}
$$

where $\beta=\frac{k}{s_{c}}$ and a higher value of $\beta$ implies a lower level of soil biodiversity (as seen from equation (1)).

The quantity of water in the soil at the end of any given period $t$ depends on the level of rainfall and the plants' demand at that period $\left(\tilde{\pi}_{t}-X_{t}\right)$, the quantity of water remaining from the previous period, $V_{t-1}$, and the soil biodiversity-water storage function $(1+\beta)$. Although not a crucial assumption, for simplicity, it is assumed that ET is the same for all development phases of the plant and that $E T$ is higher than the low level of rainfall $\pi_{l}$, as well as lower than the upper level $\pi_{h}$. Hence, $\pi_{h}=\gamma \pi_{l}$ and $E T=\alpha \pi_{l}$ with $1 \leq \alpha \leq \gamma$. Also to simplify notations in subsequent equations, let us denote $h=1+\frac{\gamma-\alpha}{1+\beta}$ where $\gamma$ is the ratio between the upper and lower level of rainfall, $(\gamma-\alpha)$ is the coefficient of rainfall water remaining in the soil once the plant demand $\alpha$ is satisfied, $h$ can thus be interpreted as a fraction of remaining rainfall water stored for the next period by soil biodiversity. When $\gamma=\alpha$, the plant water needs are satisfied by all the rainfall and there is no water to be stored by soil biodiversity.

\subsection{Soil biodiversity as natural capital in rainfed agriculture}

We consider two periods in an extended agricultural season: a first period lasting from the harvesting of the previous crop until planting of the next crop, and a second period lasting from 
planting until harvesting of the $\operatorname{crop}^{8}$. In each period either a low (drought) or a high level of rainfall can occur. This yields four scenarios or states of nature $\left(S N_{i}, i=\{1,2,3,4\}\right)$ : (a) two consecutive periods of low rainfall or droughts $\left(S N_{1}\right)$, (b) two consecutive periods of high levels of rainfall $\left(S N_{3}\right)$; (c) a drought followed by a high rainfall period $\left(S N_{2}\right)$ and a high level rainfall period followed by drought or dry spells $\left(S N_{4}\right)$. The water storage function provided by soil biodiversity occurs under $S N_{4}$ (Table 1 and Appendix A).

Table 1: Production functions under the different states of nature

\begin{tabular}{cc|cc} 
& & \multicolumn{2}{|c}{ Period 2 } \\
& & Low rainfall & High rainfall \\
\hline \multirow{2}{*}{ Period 1 } & Low rainfall & $F_{1}\left(\pi_{l}, \pi_{l}\right)$ & $F_{2}\left(\pi_{l}, \alpha \pi_{l}\right)$ \\
& High rainfall & $F_{4}\left(\alpha \pi_{l}, h \pi_{l}\right)$ & $F_{3}\left(\alpha \pi_{l}, \alpha \pi_{l}\right)$
\end{tabular}

Agricultural production depends on the amount of water taken up by the plants, $X_{t}$ during period $t=\{1,2\}$, given limited substitutability between water and other productive inputs (Schoengold et al., 2006). A standard agricultural production function, $F\left(X_{1}, X_{2}\right)$ where $F$ is increasing in each of its variables at a decreasing rates (i.e., $F^{\prime}>0$ and $F^{\prime \prime}<0$ ) is used, where $F^{\prime}$ and $F^{\prime \prime}$ represent the first and second derivatives of $F$ with respect to $X_{t}$, respectively.

Using notation from Table 1, the expected agricultural production (or expected yield) can be written as follows:

$$
E\left(F\left(X_{1}, X_{2}\right)\right)=\varphi_{l}^{2} F_{1}\left(\pi_{l}, \pi_{l}\right)+\varphi_{l} \varphi_{h} F_{2}\left(\pi_{l}, \alpha \pi_{l}\right)+\varphi_{l} \varphi_{h} F_{4}\left(\alpha \pi_{l}, h \pi_{l}\right)+\varphi_{h}^{2} F_{3}\left(\alpha \pi_{l}, \alpha \pi_{l}\right)
$$

and the marginal effect of soil biodiversity on expected crop yield by:

$$
\frac{\partial E\left(F\left(X_{1}, X_{2}\right)\right)}{\partial I_{b}}=\pi_{l}\left(\frac{L}{k}\right)^{\frac{1}{\mu}} \frac{\mu(\gamma-\alpha) \beta^{\frac{1}{\mu}+1}}{(1+\beta)^{2}} \varphi_{l} \varphi_{h}\left[F_{4}^{\prime}\left(\alpha \pi_{l}, h \pi_{l}\right)\right] \geq 0
$$

which is positive for all positive values of $I_{b}$. That is, under the given assumptions, an increase in soil biodiversity leads to an increase in expected yields under rainfall uncertainty. In other words,

\footnotetext{
${ }^{8}$ Another hypothesis giving similar results would be to consider two phases of growth of the plant during a given crop season.
} 
soil biodiversity acts as intermediate agricultural input because of the water infiltration/storage function it provides to the soil leading to water regulation services. This ecosystem service is interpreted as the capacity to improve storage of moisture in the soil which reduces the negative impact of possible dry spells or drought in any given period $t$. The positive effect of soil biodiversity is asymptotical and the impact of soil biodiversity depends mainly on the rainfall ratio parameter $\gamma$ and on the intrinsic properties of the soil, represented by parameter $k$.

The variability of crop yield can be represented by the variance of the production function (equation 7):

$$
\operatorname{Var}\left(F\left(X_{1}, X_{2}\right)\right)=E\left[\left(E\left(F\left(X_{1}, X_{2}\right)\right)-F_{i}\left(X_{1}, X_{2}\right)\right)^{2}\right]=E\left(\left(F\left(X_{1}, X_{2}\right)\right)^{2}\right)-\left[E\left(F\left(X_{1}, X_{2}\right)\right)\right]^{2}
$$

where $i=1, \ldots, 4$ indexes the state of nature (cf. Table 1 ). The marginal effect of a change in soil biodiversity on the variance of crop yields is given by:

$$
\begin{aligned}
\frac{\partial \operatorname{Var}\left(F\left(X_{1}, X_{2}\right)\right)}{\partial I_{b}} & =2\left[E\left(F\left(X_{1}, X_{2}\right) \frac{\partial F\left(X_{1}, X_{2}\right)}{\partial I_{b}}\right)-E\left(F\left(X_{1}, X_{2}\right)\right) \frac{\partial E\left(F\left(X_{1}, X_{2}\right)\right)}{\partial I_{b}}\right] \\
& =\pi_{l}\left(\frac{L}{k}\right)^{\frac{1}{\mu}} \frac{\mu(\gamma-\alpha) \beta^{\frac{1}{\mu}+1}}{(1+\beta)^{2}} \varphi_{l} \varphi_{h}\left(1-\varphi_{l} \varphi_{h}\right) F_{4}^{\prime}\left(\alpha \pi_{l}, h \pi_{l}\right)\left(F_{4}\left(\alpha \pi_{l}, h \pi_{l}\right)-\frac{\varphi_{l}^{2} F_{1}+\varphi_{l} \varphi_{h} F_{2}+\varphi_{h}^{2} F_{3}}{\varphi_{l}^{2}+\varphi_{l} \varphi_{h}+\varphi_{h}^{2}}\right)
\end{aligned}
$$

where $F_{1}=F\left(\pi_{l}, \pi_{l}\right), F_{2}=F\left(\pi_{l}, \alpha \pi_{l}\right), F_{3}=F\left(\alpha \pi_{l}, \alpha \pi_{l}\right)$.

Let us denote $\bar{\beta}$ the solution to equation (8) and $\overline{I_{b}}$ the variance minimizing level of soil biodiversity. The condition for minimizing the variance (or maximizing stability) of crop yields under stochastic rainfall is determined by setting $\frac{\partial \operatorname{Var}(F)}{\partial I_{b}}=0$, which is achieved when the yield obtained in the state of nature $S N_{4}$ (where a first wet period is followed by a dry period or a dry spell) equals the expected mean production of the other possible states of nature, $S N_{i}, i=\{1,2,3\}$. In other words, the level of soil biodiversity that minimizes the variance of yields is associated with the level that makes expected yields in $S N_{4}$ equal to the expected yields of the other states of nature.

Soil biodiversity is thus considered here as a key asset that determines expected yields in rainfed agriculture under rainfall uncertainty. Further, soil biodiversity can be managed, i.e., through 
investment in natural capital, since the soil serves as a buffer to store at least a certain fraction of water received after a period of rainfall. The underlying assumption is that the effectiveness of the soil storage capacity increases with soil biodiversity as a higher diversity of soil microorganisms contributes to build soil structure that facilitates the storage of soil moisture (Pascual et al., 2015). In the model, this storage function of the soil is possible only in state of nature $S N_{4}$, where a wet period is followed by a drier period. Hence, the expected agricultural production for the state of nature 4 increases with soil biodiversity.

In addition, the variance of yields follows a U-shape with respect to soil biodiversity (Figure 1). There exists a threshold above which the role of the input on the variance of yields is reversed, in others terms the farmers have to tradeoff an increase of expected yield with a potential increase of the variance of yields (Baumgärtner, 2007; Baumgärtner and Strunz, 2014). The variance of yields decreases as soil biodiversity increases up to a certain level of biodiversity $\left(\overline{I_{b}}\right)$, as the expected yield under $S N_{4}$ approximates the expected yield given any of the other possible states of nature, $E\left[F_{1}, F_{2}, F_{3}\right]$. Above such soil biodiversity threshold, the variance of yields increases. This occurs when the expected yield under $S N_{4}$ moves away from the expected yield of the three other states of nature. Therefore, for $I_{b}<\overline{I_{b}}$ the variance of yields decreases and then increases for $I_{b}>\overline{I_{b}}$. This also implies that soil biodiversity provides an insurance value up to a level, $\overline{I_{b}}$, beyond which such insurance mechanism weakens.

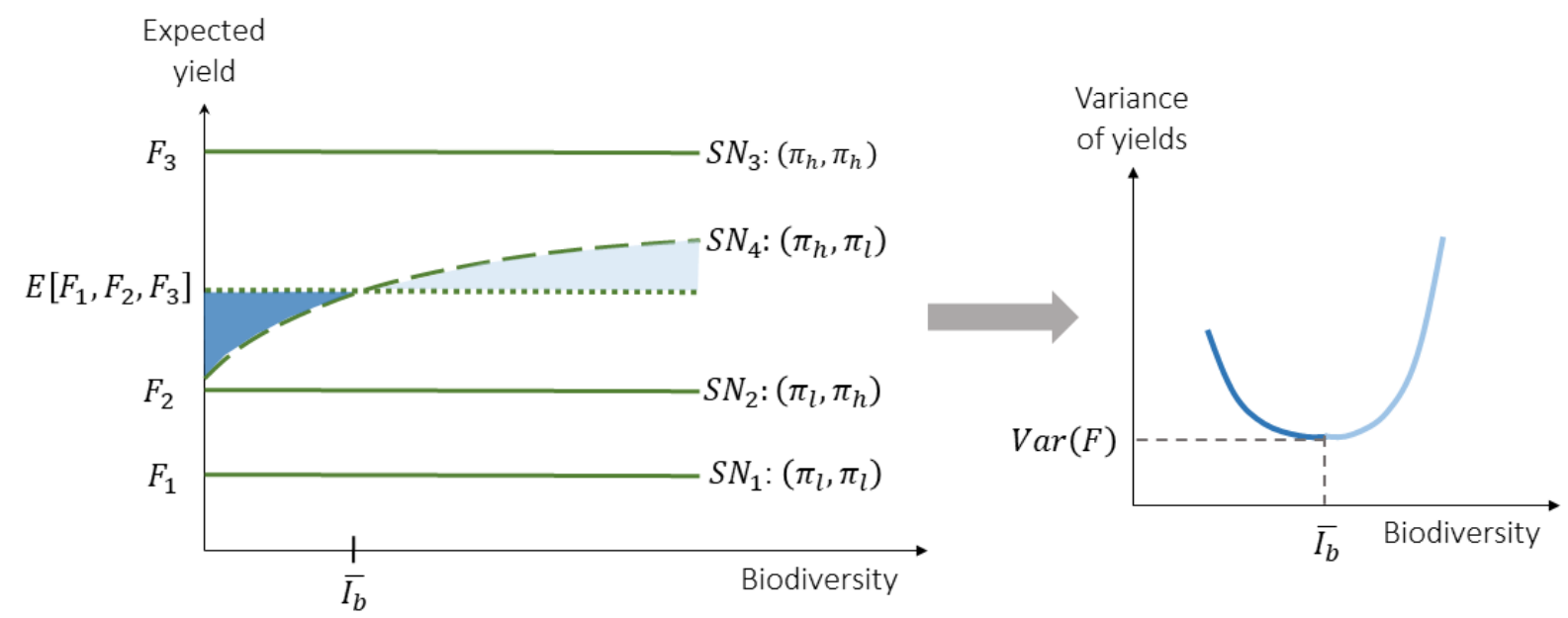

Figure 1: Expected yield and variance of yields under the different states of nature 
However, rational farmers would not necessarily aim at minimizing the variance of yields - unless they are extremely risk averse. They would rather maximize an expected profit that takes into account risks reflected by the variance of yields. Our model allows to set the following question: how would a farmer choose the optimal level of effort into conserving soil biodiversity in the context of rainfed agriculture in the global South that is prone to suffer from increased probability of droughts due to climate change? And how would farmers' risk aversion affect their soil biodiversity conservation decisions? To try to shed light on these questions, the hydro-agronomic model needs to account for economic factors, for example as regards the price of the output as well as the costs of inputs (e.g., cost of effort to conserve soil biodiversity). The next section develops the economic/decision making dimension and integrates it into the hydro-agronomic model.

\section{The role of risk aversion in natural insurance from soil biodiversity conservation}

In the case of stochastic production functions, it has been shown that an additive specification of the mean and the variance enables to disconnect the mean effect from the variance effect (Just and Pope, 1978). This means that as one factor of production increases. e.g., soil biodiversity, the specification of the model allows observing opposed effects like an increase of the mean production and a decrease of the variance. Other approaches (Antle, 1983) showed that this specification restricts the higher order moment like skewness and kurtosis to be proportional to the second moment. Here we focus our analysis on the two first moments given the lack of information on the role of biodiversity on higher order moments.

The literature generally concurs with farmers' preferences towards risk aversion, while the degree of risk aversion is seen to depend on a variety of factors including among others, wealth (Lybbert and McPeak, 2012), assets (Mosley and Verschoor, 2005), education (Tanaka et al., 2010), age and gender (Harrison et al., 2010), cultural factors (Henrich and McElreath, 2002), crop diversity (Di Falco and Chavas, 2009) or credit constraints (Boucher et al., 2009). Here we also consider a risk averse farmer, who prefers to obtain a stable agricultural income, from selling his produce, than to obtain a higher variable level of expected income. The farmer's problem is to maximize the level of expected utility, approximated by a linear mean-variance function of the market value 
of agricultural production ${ }^{9}$ (Levy and Markowitz, 1979; Markowitz, 2014), which in turn depends on the market price and the opportunity cost of soil biodiversity conservation. The economic model of soil biodiversity conservation may be written as follows:

$$
\max _{I_{b}} E\left(p F\left(X_{1}, X_{2}\right)\right)-\lambda \operatorname{Var}\left(p F\left(X_{1}, X_{2}\right)\right)-c_{b} I_{b}
$$

where $\lambda$ represents the degree of risk aversion for the farmer, with a higher value of $\lambda$ indicating a higher risk aversion; $p$ represents the unit market price of the crop and $c_{b}$ is the marginal cost of soil biodiversity conservation. This cost reflects the efforts made to conserve biodiversity through diverse soil management options, and without loss of generality, is assumed constant. The first order condition of problem (9) is stated as follows:

$$
\begin{aligned}
c_{b}= & -\pi_{l} \varphi_{l} \varphi_{h} \mu p\left(\frac{L}{k}\right) \frac{(\gamma-\alpha) \beta^{\frac{1}{\mu}+1}}{(1+\beta)^{2}} F_{4}^{\prime}\left(\alpha \pi_{l}, h \pi_{h}\right) \times \\
& \left\{p \lambda\left[\left(\varphi_{l}^{2}+\varphi_{l} \varphi_{h}+\varphi_{h}^{2}\right) F_{4}\left(\alpha \pi_{l}, h \pi_{l}\right)-\left(\varphi_{l}^{2} F_{1}+\varphi_{l} \varphi_{h} F_{2}+\varphi_{h}^{2} F_{3}\right)\right]-1\right\}
\end{aligned}
$$

Equation (10) is interpreted as the arbitrage condition: the optimal stock of soil biodiversity, $I_{b}^{*}$, is achieved when its marginal effect on the expected yield net of its marginal effect on the variance of yields (compounded by risk aversion) equals the marginal cost of soil biodiversity conservation. As it can be seen $I_{b}^{*}$ depends on factors such as the probabilities of rainfall, $\varphi_{l}$ and $\varphi_{h}$ and the associated level of rainfall $\pi_{l}$ and $\pi_{h}$, the intensity of drought $\gamma$, the rate of change of soil biodiversity $\mu$, the market price, $p$, the crop's water demand, $\alpha$, yield levels $F$ under the four states of the nature, $S N_{i}$, the marginal productivity under $S N_{4}$, and the farmer's degree of risk aversion, $\lambda$.

Equation (10) above has a closed solution when the following condition is satisfied:

$$
F_{4}\left(\alpha \pi_{1}, h \pi_{1}\right)<\frac{1}{\varphi_{l}^{2}+\varphi_{l} \varphi_{h}+\varphi_{h}^{2}}\left[\frac{1}{p \lambda}+\varphi_{l}^{2} F_{1}+\varphi_{l} \varphi_{h} F_{2}+\varphi_{h}^{2} F_{3}\right]
$$

as otherwise the marginal cost of biodiversity conservation would be negative. If equation (11) does not hold then the optimal level of investment in soil biodiversity resulting from equation (10) would be zero. We focus only on the closed-form solution where equation (11) holds.

\footnotetext{
${ }^{9}$ This approach already used by Levy and Markovitz (1979) has the advantage that the model is mathematically more tractable for empirical research than generalized forms of utility (Coyle, 1992).
} 
The arbitrage condition (10) once rearranged is composed by (i) a term representing the marginal productivity under the state of nature $S N_{4}$, i.e., when water is storable between periods, and (ii) a term representing the coverage against risk aversion. That is, soil biodiversity has both an indirect output value and a natural insurance value (Pascual et al., 2015). An expected result from the mean-variance approach is that the natural insurance value is positive as long as soil biodiversity decreases the variance of yields, and negative otherwise. To further understand the conditions supporting a positive natural insurance value, we focus on how risk aversion affects the farmer's optimal decision on soil biodiversity conservation, i.e. the marginal effect of $\lambda$ on $\beta^{*}$. To that end, we differentiate equation (10) with respect to $\lambda$ :

$$
\begin{gathered}
\frac{\partial \beta^{*}}{\partial \lambda}=\left[-\frac{\partial G(\beta)}{\partial \beta}\left\{p \lambda\left[\left(\varphi_{l}^{2}+\varphi_{l} \varphi_{h}+\varphi_{h}^{2}\right) F_{4}\left(\alpha \pi_{l}, h \pi_{l}\right)-\left(\varphi_{l}^{2} F_{1}+\varphi_{l} \varphi_{h} F_{2}+\varphi_{h}^{2} F_{3}\right)\right]-1\right\}\right. \\
\left.+G(\beta)\left(\varphi_{l}^{2}+\varphi_{l} \varphi_{h}+\varphi_{h}^{2}\right)\left(\pi_{1} \frac{\gamma-\alpha}{(1+\beta)^{2}}\right) F_{4}^{\prime}\left(\alpha \pi_{1}, h \pi_{1}\right)\right]^{-1} \\
\times\left[\left(\varphi_{l}^{2}+\varphi_{l} \varphi_{h}+\varphi_{h}^{2}\right) F_{4}\left(\alpha \pi_{l}, h \pi_{l}\right)-\left(\varphi_{l}^{2} F_{1}+\varphi_{l} \varphi_{h} F_{2}+\varphi_{h}^{2} F_{3}\right)\right]
\end{gathered}
$$

with $G(\beta)=\frac{(\gamma-\alpha) \beta^{\frac{1}{\mu}+1}}{(1+\beta)^{2}} F_{4}^{\prime}\left(\alpha \pi_{l}, h \pi_{l}\right)$.

The sign of $\frac{\partial \beta}{\partial \lambda}$ depends on the sign of expression $\left[\left(\varphi_{l}^{2}+\varphi_{l} \varphi_{h}+\varphi_{h}^{2}\right) F_{4}\left(\alpha \pi_{l}, h \pi_{l}\right)-\left(\varphi_{l}^{2} F_{1}+\right.\right.$ $\left.\left.\varphi_{l} \varphi_{h} F_{2}+\varphi_{h}^{2} F_{3}\right)\right]$ considering equation (11) and the fact that $G(\beta)$ is increasing in $\beta$. To study this sign, we first draw the condition under which risk aversion has no influence on $\beta$ and derive the corresponding marginal cost of conservation $\overline{c_{b}}$. Then, we compare this case to a situation where risk aversion has an influence on $\beta$.

Let us note $\bar{\beta}$ the solution to the equation $\left(\varphi_{l}^{2}+\varphi_{l} \varphi_{h}+\varphi_{h}^{2}\right) F_{4}\left(\alpha \pi_{l}, h \pi_{l}\right)-\left(\varphi_{l}^{2} F_{1}+\varphi_{l} \varphi_{h} F_{2}+\right.$ $\left.\varphi_{h}^{2} F_{3}\right)=0 . \bar{I}_{b}(\bar{\beta})$ is then the level of biodiversity associated with a degree of risk aversion that does not influence the stock of soil biodiversity, i.e. $\frac{\partial \beta}{\partial \lambda}=0$. Applying the arbitrage condition (10) to the case where risk aversion does not influence soil biodiversity level, we know that a level of soil biodiversity $\bar{I}_{b}(\bar{\beta})$ will be achieved when:

$$
\overline{c_{b}}=\pi_{l} \varphi_{l} \varphi_{h} \mu p\left(\frac{L}{k}\right) \frac{(\gamma-\alpha) \bar{\beta}^{1+\frac{1}{\mu}}}{(1+\bar{\beta})^{2}} F_{4}^{\prime}\left(\alpha \pi_{l}, \bar{h} \pi_{l}\right)
$$


$\overline{c_{b}}$ being the level of marginal cost of biodiversity conservation for which risk aversion does not influence the level of soil biodiversity conservation decision and the variance of yields is at minimum (i.e., setting equation (12) equal to zero ${ }^{10}$ ). For any other level of soil biodiversity different from $\bar{I}_{b}(\bar{\beta})$, the variance of yields is not minimized and soil biodiversity is either a risk increasing or a risk decreasing factor given the variance function, shown in Figure 2 through a simple parameterization (see appendix B, Table B1). If the marginal cost of soil biodiversity conservation is lower than the level $\overline{c_{b}}$, the farmer is on the right side of the variance curve where any additional level of soil biodiversity increases the variance of crop yields, consequently, a more risk averse farmer will tend to disinvest in soil biodiversity ${ }^{11}$. But when $c_{b}>\overline{c_{b}}$, the farmer is on the decreasing part of the variance curve and the risk averse farmer will invest in increasing soil biodiversity due to its natural insurance value, besides increasing mean yield.

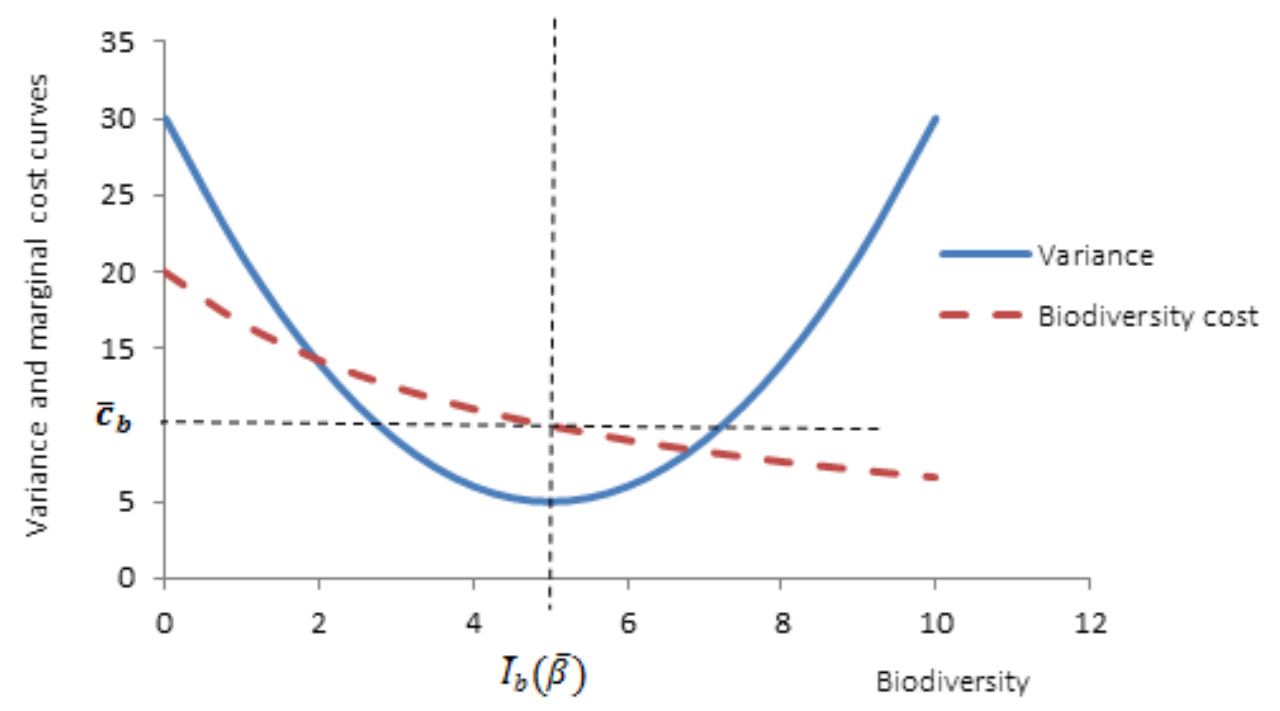

Figure 2: Variance of yields and cost functions superimposed. As the variance of yields is decreasing, soil biodiversity has both an indirect output value and an insurance (left hand side of $\overline{\boldsymbol{I}}_{\boldsymbol{b}}$ ). As it is increasing, soil biodiversity has only an indirect output value (right hand side of $\overline{\boldsymbol{I}}_{\boldsymbol{b}}$ ). Parameters of the functions are summarized in appendix B, Table B1.

\footnotetext{
${ }^{10}$ By construction of the model the optimal condition $\overline{c_{b}}$ is also the optimal condition under risk neutrality.

${ }^{11}$ Here we use a very simple linear model of the costs of biodiversity investment. Disinvestment simply means that it will be optimal to invest less in biodiversity and incur lower cost of biodiversity conservation.
} 
It can be noted from equation (10) that the marginal cost $c_{b}$, is proportional to agricultural productivity. This suggests that, ceteris paribus, farmers growing very productive crops under rainfed agriculture, would be more likely to rely on soil biodiversity for its productive use only, while farmers with lower productivity crops would use soil biodiversity conservation strategies partly for its productive value and partly for its natural insurance value.

\section{The impact of climate variability on soil biodiversity decisions}

An increase in the frequency or probability of drought in rainfed agricultural systems, such as those in the global South, and especially in SSA, is one of the major effects of climate change (IPCC, 2013). We can use our model to analyze the relationship between an increase in the frequency of droughts and optimal soil biodiversity conservation decisions. Let us reconsider the first order condition of the optimization problem (9). The solution to that problem has been presented in equation (10) from which we can derive the marginal effect of drought frequency on the optimal level of the stock of soil biodiversity:

$$
\begin{aligned}
& \frac{\partial I_{b}^{*}}{\partial \varphi_{l}}=\frac{1}{\left(\frac{L}{k}\right)^{\frac{1}{\mu}} \mu \beta^{\frac{1}{\mu}+1}} \times \\
& {\left[-G^{\prime}(\beta)\left\{p \lambda\left[\left(\varphi_{l}^{2}+\varphi_{l} \varphi_{h}+\varphi_{h}^{2}\right) F_{4}\left(\alpha \pi_{l}, h \pi_{l}\right)-\left(\varphi_{l}^{2} F_{1}+\varphi_{l} \varphi_{h} F_{2}+\varphi_{h}^{2} F_{3}\right)\right]-1\right\}\right.} \\
& \left.\quad+p \lambda G(\beta) \frac{\gamma-\alpha}{(1+\beta)} \pi_{l}\left(\varphi_{l}^{2}+\varphi_{l} \varphi_{h}+\varphi_{h}^{2}\right) F_{4}\left(\alpha \pi_{l}, h \pi_{l}\right)\right]^{-1} \\
& \quad \times\left[\frac{c_{b}\left(1-2 \varphi_{l}\right)}{\left(\varphi_{l}\left(1-\varphi_{l}\right)\right)^{2}}+p \lambda\left\{\left(1-2 \varphi_{l}\right) F_{4}\left(\alpha \pi_{l}, h \pi_{l}\right)+\left(\varphi_{l} 2\left(F_{1}-F_{2}-F_{3}\right)+F_{2}-2 F_{3}\right)\right\}\right]
\end{aligned}
$$

In the general case of risk aversion:

$$
\lim _{\varphi_{l} \rightarrow 0} \frac{\partial I_{b}^{*}}{\partial \varphi_{l}}=+\infty \text { and } \lim _{\varphi_{l} \rightarrow 1} \frac{\partial I_{b}^{*}}{\partial \varphi_{l}}=-\infty
$$

This implies that for the general case, there is at least an interval (a range of drought frequencies) where $I_{b}^{*}$ increases with $\varphi_{l}$ and at least another interval where $I_{b}^{*}$ decreases with $\varphi_{l}$. The implication is that an increase in drought frequency could in principle lead to either an increased or decreased biodiversity conservation effort. Let's analyze this result. Consider the special case when the farmer is not sensitive to risk, $\lambda=0$. Then under risk neutrality, equation (13) becomes: 
$\frac{\partial I_{b}^{*}}{\partial \varphi_{l}}=\frac{1}{\pi_{l}\left(\frac{L}{k}\right)^{\frac{2}{\mu} \mu(\gamma-\alpha)\left(\varphi_{l}\left(1-\varphi_{l}\right)\right)^{2} \beta^{\frac{1}{\mu}+1}}} \times \frac{c_{b}\left(1-2 \varphi_{l}\right)}{(1+\beta)^{4}} \times \frac{\left.\beta^{\frac{1}{\mu}}(1+\beta)\left(1+\frac{1}{\mu}+\beta\left(\frac{1-\mu}{\mu}\right)\right) F_{4}^{\prime}\left(\alpha \pi_{l}, h \pi_{l}\right)-\pi_{l}(\gamma-\alpha) F_{4}^{\prime \prime}\left(\alpha \pi_{l}, h \pi_{l}\right)\right]}{}$

and it is now possible to analyze the variation of $I_{b}$ with respect to $\varphi_{l}$. In other words, we can infer how the optimal biodiversity level changes with drought frequency in the specific case of a risk neutral farmer.

We know that $\left[\beta^{\frac{1}{\mu}}(1+\beta)\left(1+\frac{1}{\mu}+\beta\left(\frac{1-\mu}{\mu}\right)\right) F_{4}^{\prime}\left(\alpha \pi_{l}, h \pi_{l}\right)-\pi_{l}(\gamma-\alpha) F_{4}^{\prime \prime}\left(\alpha \pi_{l}, h \pi_{l}\right)\right]>0$ since: $F_{4}^{\prime}\left(\alpha \pi_{l}, h \pi_{l}\right)>0$ and $F_{4}^{\prime \prime}\left(\alpha \pi_{l}, h \pi_{l}\right)<0 ; \gamma-\alpha>0$ and $\varphi_{l}\left(1-\varphi_{l}\right)>0$. Thus the sign of $\frac{\partial I_{b}^{*}}{\partial \varphi_{l}}$ depends on the sign of expression $\left(1-2 \varphi_{l}\right)$. For $0<\varphi_{l}<0.5$, we have $\frac{\partial I_{b}^{*}}{\partial \varphi_{l}}>0$ and for $0.5<\varphi_{l}$ $<1$, we have $\frac{\partial I_{b}^{*}}{\partial \varphi_{l}}<0$.

A numerical simulation clarifies the result further (Figure 3$)^{12}$. In the case of risk neutrality $(\lambda=$ 0 ), for relatively low probability (or frequency) of drought occurring (i.e., $0<\varphi_{l}<0.5$ ) a marginal increase of drought frequency has a positive impact on $I_{b}^{*}$ whereas for relatively high drought frequencies, the marginal effect is negative, that is, the farmer is discouraged to further conserve soil biodiversity. The intuition behind this result is that below a certain threshold of drought frequency $\left(\varphi_{l}<0.5\right.$ as per Figure 3$)$, when the probability of drought increases, it is rational to invest in enhancing the stock of soil biodiversity because this allows keeping soil moisture in the first period (i.e., intercrop period or first phase of plant growth) and store it for the second period when the probability of drought may increase. This moisture storage function by soil biodiversity allows the farmer to reduce the negative effects on expected yields in case of drought occurring in the second period. This role of soil biodiversity allows the agricultural system to be more

\footnotetext{
${ }^{12}$ We use numerical simulations to study how the optimal level of biodiversity varies with drought frequency and for different degrees of risk aversion. We use the production function estimated by Terreaux et al. (2012) and their rainfall levels (see also appendix B, Table B1).
} 
productive in a situation of increased probability of droughts, e.g., due to climate change. But beyond a certain level $\left(\varphi_{l}=0.5\right)$, droughts become so frequent that it becomes less likely for the soil to retain enough water in the first period for plant uptake as well as to store moisture for the second period; that is, the water regulating service provided by soil biodiversity is compromised beyond a probability threshold for drought occurrence. This means that farmers do not have incentives to invest in soil biodiversity.

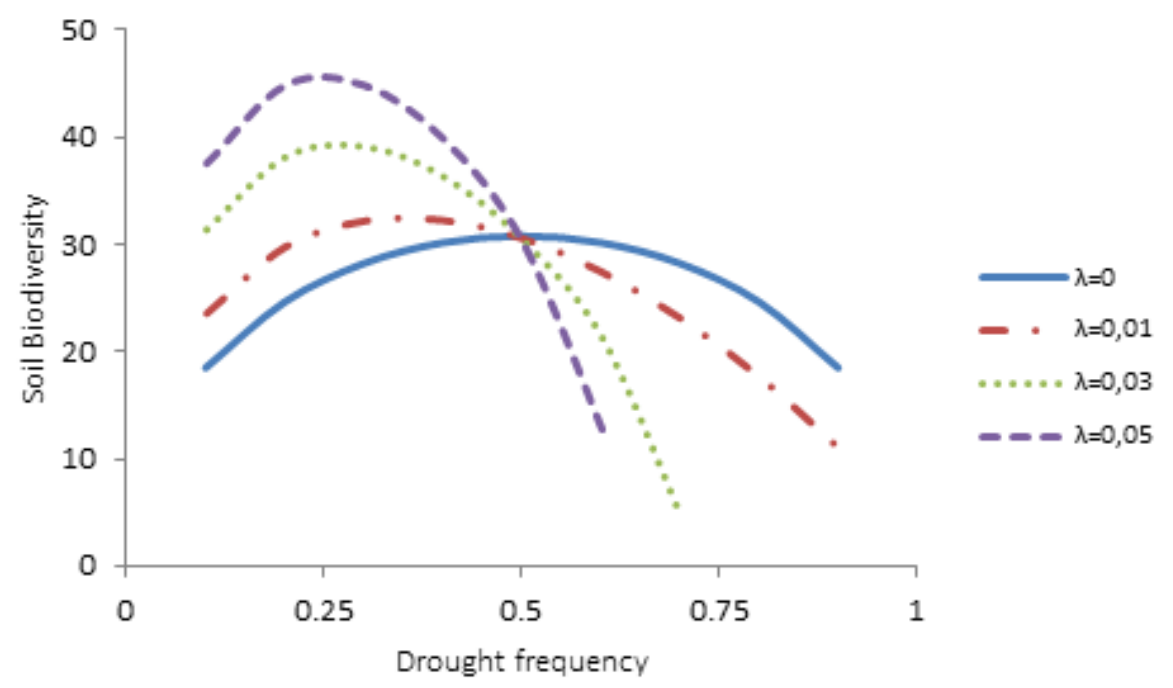

Figure 3: Soil biodiversity conservation in function of drought for varying levels of risk aversion. It represents the function $\boldsymbol{I}_{b}\left(\boldsymbol{\varphi}_{l}\right)$ for different degrees of risk aversion $\lambda$ and for $\mu=0.5, \alpha=1.1$

A risk averse farmer $(\lambda>0)$ will follow the same rationale about investing in soil biodiversity in terms of optimizing yield levels. But given the natural insurance provided by soil biodiversity to a risk averse farmer, such farmer would invest more in soil biodiversity than a risk neutral farmer $(\lambda=0)$ and disinvest earlier when the probability of drought increases, in context of relatively low drought frequencies ${ }^{13}$ (Figure 3 ). The natural insurance value of biodiversity is thus contingent to a large extent on the level of risk aversion and on the frequency of the event to be insured against. Moreover, while it may appear at first, that the higher the probability of drought occurring in rainfed systems, the larger the role of soil biodiversity to buffer against crop failure, this only

\footnotetext{
${ }^{13}$ A sensitivity analysis has been performed for different values of the parameters of the first order condition. It indicates that the tendency observed here is stable and consistent. Results are available upon request.
} 
holds up to a given drought probability threshold. Beyond this point, soil biodiversity would be optimally disinvested. This indicates that the value of natural insurance in drought prone rainfed systems may be non-linear and that investing in soil biodiversity alone might not be sufficient to maintain soil moisture beyond a threshold of drought frequency.

\section{Conclusion}

Our bioeconomic model, based on the role of soil biodiversity and water regulation services establishes an ecological-economic link between soil biodiversity, its water storage function leading to water regulating ecosystem service, and the economic rationale of a utility maximizing farmer with risk aversion to the variability of rainfall. The theoretical results have two major implications in terms of policies about climate change adaptation in rainfed, low input agricultural systems, especially as those being used in much of the global South and sub-Saharan African, in particular.

First, taking into account farmers' risk aversion, the conservation of soil biodiversity is important both in terms of its productivity and natural insurance role against the fluctuations of agricultural income resulting from rainfall variability, as pointed by Pascual et al. (2015). This result is also in line with other theoretical models (e.g., Quaas and Baumgärtner, 2008). Conditions under which soil biodiversity conservation increases agricultural production and reduces the variance of yields can be made explicit. These conditions directly depend on the opportunity cost of biodiversity conservation. According to our model, agri-environmental measures should be designed to reduce this cost to incentivize risk averse farmers to conserve soil biodiversity to adapt to climate change, e.g., through climate robust agroecological practices.

Second, more frequent droughts as a result of climate change, require increased investments in soil biodiversity conservation as this would allow reducing the negative impact of droughts on farmers' profits and stabilizing their income. A possible policy is to increase the awareness of farmers of the different regulation services offered by soil biodiversity and how to adopt best practices for soil biodiversity conservation.

However, a key result of the model is also that beyond a given level of drought frequency, increasing soil biodiversity conservation may lead to suboptimal outcomes from a farmer's private 
perspective. This is because, relative to the cost of biodiversity conservation, the level of the additional water regulation services it provides, might be reduced. This threshold effect depends on economic parameters such as crop prices, risk preferences and the agro-economic context.

Despite its theoretical simplicity, the results of this bioeconomic model offer insights and hypotheses that require further empirical investigation. We think that these two results will help better locate the role of soil biodiversity for climate adaptation within broader climate smart agricultural strategies, especially in those regions, such as sub Saharan Africa, where climate change is expected to hit vulnerable farmers in rainfed systems, disproportionally.

Acknowledgements: This paper has received funding from the European Union Seventh Framework Programme (FP7/ 2007-2013) under the grant agreement n 264465 (EcoFINDERS). The authors want to acknowledge support from Aarhus University, Department of Environmental Science, Denmark, as Mette Termansen was affiliated to the institute during the Ecofinders project.

\section{References}

Allison, F.., 1973. Soil Organic Matter and its Role in Crop Production, Elsevier. ed.

Altieri, M.A., 1999. The ecological role of biodiversity in agroecosystems. Agric. Ecosyst. Environ. 74, 19-31. https://doi.org/10.1016/S0167-8809(99)00028-6

Antle, J.M., 1987. Econometric Estimation of Producers' Risk Attitudes. Am. J. Agric. Econ. 69, 509-522. https://doi.org/10.2307/1241687

Antle, J.M., 1983. Testing the Stochastic Structure of Production: A Flexible Moment-Based Approach. J. Bus. Econ. Stat. 1, 192-201. https://doi.org/10.2307/1391337

Bardgett, R.D., Anderson, J.M., Behan-Pelletier, V., Brussaard, L., Coleman, D.C., Ettema, C., Moldenke, A., Schimel, J.P., Wall, D.H., 2001. The Influence of Soil Biodiversity on Hydrological Pathways and the Transfer of Materials between Terrestrial and Aquatic Ecosystems. Ecosystems 4, 421-429. https://doi.org/10.1007/s10021-001-0020-5

Barrios, E., 2007. Soil biota, ecosystem services and land productivity. Ecol. Econ. 64, 269-285. https://doi.org/10.1016/j.ecolecon.2007.03.004

Bastardie, F., Ruy, S., Cluzeau, D., 2005. Assessment of earthworm contribution to soil hydrology: a laboratory method to measure water diffusion through burrow walls. Biol. Fertil. Soils 41, 124-128. https://doi.org/10.1007/s00374-004-0817-4

Baumgärtner, S., 2007. The Insurance Value of Biodiversity in the Provision of Ecosystem Services. Nat. Resour. Model. 20, 87-127. https://doi.org/10.1111/j.19397445.2007.tb00202.x 
Baumgärtner, S., Quaas, M.F., 2010. Managing increasing environmental risks through agrobiodiversity and agrienvironmental policies. Agric. Econ. 41, 483-496. https://doi.org/10.1111/j.1574-0862.2010.00460.x

Baumgärtner, S., Strunz, S., 2014. The economic insurance value of ecosystem resilience. Ecol. Econ. 101, 21-32. https://doi.org/10.1016/j.ecolecon.2014.02.012

Bengtsson, J., 1998. Which species? What kind of diversity? Which ecosystem function? Some problems in studies of relations between biodiversity and ecosystem function. Appl. Soil Ecol. 10, 191-199. https://doi.org/10.1016/S0929-1393(98)00120-6

Bewket, W., 2007. Soil and water conservation intervention with conventional technologies in northwestern highlands of Ethiopia: Acceptance and adoption by farmers. Land Use Policy 24, 404-416. https://doi.org/10.1016/j.landusepol.2006.05.004

Biazin, B., Sterk, G., Temesgen, M., Abdulkedir, A., Stroosnijder, L., 2012. Rainwater harvesting and management in rainfed agricultural systems in sub-Saharan Africa - A review. Phys. Chem. Earth Parts ABC, Recent Advances in Water Resources Management 47-48, 139-151. https://doi.org/10.1016/j.pce.2011.08.015

Boucher, S.R., Guirkinger, C., Trivelli, C., 2009. Direct Elicitation of Credit Constraints: Conceptual and Practical Issues with an Application to Peruvian Agriculture. Econ. Dev. Cult. Change 57, 609-640. https://doi.org/10.1086/598763

Brock, W.A., Finnoff, D., Kinzig, A.P., Pascual, U., Perrings, C., Tschirhart, J., Xepapadeas, A., 2009. Modelling biodiversity and ecosystem services in coupled ecological-economic systems, in: Biodiversity, Ecosystem Functioning, and Human Wellbeing: An Ecological and Economic Perspective. Naeem S., D. Bunker, A. Hector, M. Loreau and C. Perrings, Oxford, UK.

Brussaard, L., 1997. Biodiversity and Ecosystem Functioning in Soil. Ambio 26, 563-570.

Challinor, A., Wheeler, T., Garforth, C., Craufurd, P., Kassam, A., 2007. Assessing the vulnerability of food crop systems in Africa to climate change. Clim. Change 83, 381399. https://doi.org/10.1007/s10584-007-9249-0

Chavas, J.-P., Falco, S.D., 2012. On the Productive Value of Crop Biodiversity: Evidence from the Highlands of Ethiopia. Land Econ. 88, 58-74. https://doi.org/10.3368/le.88.1.58

Cooper, P.J.M., Dimes, J., Rao, K.P.C., Shapiro, B., Shiferaw, B., Twomlow, S., 2008. Coping better with current climatic variability in the rain-fed farming systems of sub-Saharan Africa: An essential first step in adapting to future climate change? Agric. Ecosyst. Environ., International Agricultural Research and Climate Change: A Focus on Tropical Systems 126, 24-35. https://doi.org/10.1016/j.agee.2008.01.007

Coyle, B.T., 1992. Risk Aversion and Price Risk in Duality Models of Production: A Linear Mean-Variance Approach. Am. J. Agric. Econ. 74, 849-859. https://doi.org/10.2307/1243182

De Deyn, G.B., Van der Putten, W.H., 2005. Linking aboveground and belowground diversity. Trends Ecol. Evol. 20, 625-633. https://doi.org/10.1016/j.tree.2005.08.009

Di Falco, S., Chavas, J.-P., 2009. On Crop Biodiversity, Risk Exposure, and Food Security in the Highlands of Ethiopia. Am. J. Agric. Econ. 91, 599-611. https://doi.org/10.1111/j.14678276.2009.01265.x

Di Falco, S., Chavas, J.-P., 2008. Rainfall shocks, resilience, and the effects of crop biodiversity on agroecosystem productivity. Land Econ. 84, 83-96. 
Edwards, C.., Arancon, N.., 2004. Interactions among Organic Matter, Earthworms, and Microorganisms in Promoting Plant Growth, in: Soil Organic Matter in Sustainable Agriculture, Advances in Agroecology. CRC Press, pp. 327-376. https://doi.org/10.1201/9780203496374.ch11

Falkenmark, M., Rockström, J., 2008. Building resilience to drought in desertification-prone savannas in Sub-Saharan Africa: The water perspective. Nat. Resour. Forum 32, 93-102. https://doi.org/10.1111/j.1477-8947.2008.00177.x

FAO, 2014. FAO Statistical Yearbook 2014: Africa food and agriculture.

Finger, R., Buchmann, N., 2015. An ecological economic assessment of risk-reducing effects of species diversity in managed grasslands. Ecol. Econ. 110, 89-97. https://doi.org/10.1016/j.ecolecon.2014.12.019

Foudi, S., 2012. The role of farmers' property rights in soil ecosystem services conservation. Ecol. Econ. 83, 90-96. https://doi.org/10.1016/j.ecolecon.2012.08.015

Funk, C., Dettinger, M.D., Michaelsen, J.C., Verdin, J.P., Brown, M.E., Barlow, M., Hoell, A., 2008. Warming of the Indian Ocean threatens eastern and southern African food security but could be mitigated by agricultural development. Proc. Natl. Acad. Sci. 105, 1108111086. https://doi.org/10.1073/pnas.0708196105

Giller, K.E., Witter, E., Corbeels, M., Tittonell, P., 2009. Conservation agriculture and smallholder farming in Africa: The heretics' view. Field Crops Res. 114, 23-34. https://doi.org/10.1016/j.fcr.2009.06.017

Gupta, S.C., Larson, W.E., 1979. Estimating soil water retention characteristics from particle size distribution, organic matter percent, and bulk density. Water Resour. Res. 15, 16331635. https://doi.org/10.1029/WR015i006p01633

Harrison, G.W., Humphrey, S.J., Verschoor, A., 2010. Choice under Uncertainty: Evidence from Ethiopia, India and Uganda*. Econ. J. 120, 80-104. https://doi.org/10.1111/j.14680297.2009.02303.x

Hector, A., Bagchi, R., 2007. Biodiversity and ecosystem multifunctionality. Nature 448, 188190. https://doi.org/10.1038/nature05947

Henrich, J., McElreath, R., 2002. Are Peasants Risk-Averse Decision Makers? Curr. Anthropol. 43, 172-181.

Hobbs, P.R., Sayre, K., Gupta, R., 2008. The role of conservation agriculture in sustainable agriculture. Philos. Trans. R. Soc. Lond. B Biol. Sci. 363, 543-555. https://doi.org/10.1098/rstb.2007.2169

Hudson, B.D., 1994. Soil organic matter and available water capacity. J. Soil Water Conserv. 49, 189-194.

IPCC, 2013. Summary for policy maker, in: Climate Change 2013: The Physical Science Basis. Contribution of Working Group I to the Fifth Assessment Report of the Intergovernmental Panel on Climate Change. Stocker, T.F., D. Qin, G.-K. Plattner, M. Tignor, S. K. Allen, J. Boschung, A. Nauels, Y. Xia, V. Bex and P.M. Midgley, Cambridge, United Kingdom and New York, NY, USA.

Jhonson, C., 2009. Biology of Soil Science, Oxford Book Company. ed. Jaipur, India.

Just, D.R., Peterson, H.H., 2010. Is Expected Utility Theory Applicable? A Revealed Preference Test. Am. J. Agric. Econ. 92, 16-27. https://doi.org/10.1093/ajae/aap015

Just, R.., 2008. Distinguishing Preferences from Perceptions for Meaningful Policy Analysis. Am. J. Agric. Econ. 90, 1165-1175. 
Just, R.E., Just, D.R., 2011. Global identification of risk preferences with revealed preference data. J. Econom., The Economics and Econometrics of Risk 162, 6-17. https://doi.org/10.1016/j.jeconom.2009.10.004

Just, R.E., Pope, R.D., 1979. Production Function Estimation and Related Risk Considerations. Am. J. Agric. Econ. 61, 276-284. https://doi.org/10.2307/1239732

Just, R.E., Pope, R.D., 1978. Stochastic specification of production functions and economic implications. J. Econom. 7, 67-86. https://doi.org/10.1016/0304-4076(78)90006-4

Kadigi, R.M.., Tesfay, G., Bizoza, A., Zinabou, G., 2012. Irrigation and Water Use Efficiency in Sub-Saharan Africa. Policy Research Paper 4. Global Development Network.

Kirkham, M.B., 2005. Principles of soil and plant water relations, Elsevier. ed.

Lence, S.H., 2009. Joint Estimation of Risk Preferences and Technology: Flexible Utility or Futility? Am. J. Agric. Econ. 91, 581-598.

Levy, H., Markowitz, H.M., 1979. Approximating Expected Utility by a Function of Mean and Variance. Am. Econ. Rev. 69, 308-317.

Lybbert, T.J., McPeak, J., 2012. Risk and intertemporal substitution: Livestock portfolios and off-take among Kenyan pastoralists. J. Dev. Econ. 97, 415-426. https://doi.org/10.1016/j.jdeveco.2011.06.004

Markowitz, H., 2014. Mean-variance approximations to expected utility. Eur. J. Oper. Res., 60 years following Harry Markowitz's contribution to portfolio theory and operations research 234, 346-355. https://doi.org/10.1016/j.ejor.2012.08.023

Mosley, P., Verschoor, A., 2005. Risk Attitudes and the 'Vicious Circle of Poverty.' Eur. J. Dev. Res. 17, 59-88. https://doi.org/10.1080/09578810500066548

Niang, I., Ruppel, O.C., 2014. Africa, in: Climate Change 2014: Impacts, Adaptation and Vulnerability. Working Group II Contribution to the IPCC 5th Assessment Report.

Nielsen, U.N., Ayres, E., Wall, D.H., Bardgett, R.D., 2011. Soil biodiversity and carbon cycling: a review and synthesis of studies examining diversity-function relationships. Eur. J. Soil Sci. 62, 105-116. https://doi.org/10.1111/j.1365-2389.2010.01314.x

Omer, A., Pascual, U., Russell, N., 2010. A theoretical model of agrobiodiversity as a supporting service for sustainable agricultural intensification. Ecol. Econ. 69, 1926-1933. https://doi.org/10.1016/j.ecolecon.2010.04.025

Pascual, U., Balvanera, P., Díaz, S., Pataki, G., Roth, E., Stenseke, M., Watson, R.T., Başak Dessane, E., Islar, M., Kelemen, E., Maris, V., Quaas, M., Subramanian, S.M., Wittmer, H., Adlan, A., Ahn, S., Al-Hafedh, Y.S., Amankwah, E., Asah, S.T., Berry, P., Bilgin, A., Breslow, S.J., Bullock, C., Cáceres, D., Daly-Hassen, H., Figueroa, E., Golden, C.D., Gómez-Baggethun, E., González-Jiménez, D., Houdet, J., Keune, H., Kumar, R., Ma, K., May, P.H., Mead, A., O'Farrell, P., Pandit, R., Pengue, W., Pichis-Madruga, R., Popa, F., Preston, S., Pacheco-Balanza, D., Saarikoski, H., Strassburg, B.B., van den Belt, M., Verma, M., Wickson, F., Yagi, N., 2017. Valuing nature's contributions to people: the IPBES approach. Curr. Opin. Environ. Sustain. 26, 7-16. https://doi.org/10.1016/j.cosust.2016.12.006

Pascual, U., Jackson, L.E., Drucker, A.G., 2013. Economics of Agrobiodiversity, in: Simon A. Levin (Ed.), Encyclopedia of Biodiversity (Second Edition). Elsevier, Waltham, pp. 3144. 
Pascual, U., Narloch, U., Nordhagen, S., Drucker, A.G., 2011. The economics of agrobiodiversity conservation for food security under climate change. Econ. Agrar. Recur. Nat. 11, 191-220.

Pascual, U., Termansen, M., Hedlund, K., Brussaard, L., Faber, J.H., Foudi, S., Lemanceau, P., Jørgensen, S.L., 2015. On the value of soil biodiversity and ecosystem services. Ecosyst. Serv. 15, 11-18. https://doi.org/10.1016/j.ecoser.2015.06.002

Pittelkow, C.M., Liang, X., Linquist, B.A., Groenigen, K.J. van, Lee, J., Lundy, M.E., Gestel, N. van, Six, J., Venterea, R.T., Kessel, C. van, 2014. Productivity limits and potentials of the principles of conservation agriculture. Nature 517. https://doi.org/10.1038/nature13809

Quaas, M.F., Baumgärtner, S., 2008. Natural vs. financial insurance in the management of public-good ecosystems. Ecol. Econ. 65, 397-406. https://doi.org/10.1016/j.ecolecon.2007.07.004

Rockström, J., Karlberg, L., Wani, S.P., Barron, J., Hatibu, N., Oweis, T., Bruggeman, A., Farahani, J., Qiang, Z., 2010. Managing water in rainfed agriculture-The need for a paradigm shift. Agric. Water Manag., Comprehensive Assessment of Water Management in Agriculture 97, 543-550. https://doi.org/10.1016/j.agwat.2009.09.009

Rogers, P., De Silva, R., Bhatia, R., 2002. Water is an economic good: how to use prices to promote equity, efficiency, and sustainability. Water Policy 4, 1-17.

Roscoe, K.H., 1968. Soils and model tests. J. Strain Anal. 3, 57-64. https://doi.org/10.1243/03093247V031057

Rosegrant, M.W., Cline, S.A., 2003. Global Food Security: Challenges and Policies. Science 302, 1917-1919. https://doi.org/10.1126/science.1092958

Roudier, P., Sultan, B., Quirion, P., Berg, A., 2011. The impact of future climate change on West African crop yields: What does the recent literature say? Glob. Environ. Change-Hum. Policy Dimens. 21, 1073-1083. https://doi.org/10.1016/j.gloenvcha.2011.04.007

Schmidhuber, J., Tubiello, F.N., 2007. Global food security under climate change. Proc. Natl. Acad. Sci. 104, 19703-19708. https://doi.org/10.1073/pnas.0701976104

Schoengold, K., Sunding, D.L., Moreno, G., 2006. Price elasticity reconsidered: Panel estimation of an agricultural water demand function. Water Resour. Res. 42, W09411. https://doi.org/10.1029/2005WR004096

Smakhtin, V., 2002. Environmental water needs and impacts of irrigated agriculture in river basins: A framework for a new research program (Working Paper). International Water Management Institute (IWMI).

Spurgeon, D.J., Keith, A.M., Schmidt, O., Lammertsma, D.R., Faber, J.H., 2013. Land-use and land-management change: relationships with earthworm and fungi communities and soil structural properties. BMC Ecol. 13, 46. https://doi.org/10.1186/1472-6785-13-46

Swift, M.J., Izac, A.-M.N., van Noordwijk, M., 2004. Biodiversity and ecosystem services in agricultural landscapes - are we asking the right questions? Agric. Ecosyst. Environ., Environmental Services and Land Use Change: Bridging the Gap between Policy and Research in Southeast Asia 104, 113-134. https://doi.org/10.1016/j.agee.2004.01.013

Tanaka, T., Camerer, C.F., Nguyen, Q., 2010. Risk and Time Preferences: Linking Experimental and Household Survey Data from Vietnam. Am. Econ. Rev. 100, 557-571. https://doi.org/10.1257/aer.100.1.557 
Terreaux, J.-P., Sidibe, Y., Tidball, M., 2012. Préservation des étiages par des méthodes originales de tarification de l'eau d'irrigation. Houille Blanche 41-46. https://doi.org/10.1051/lhb/2012038

Tscharntke, T., Clough, Y., Wanger, T.C., Jackson, L., Motzke, I., Perfecto, I., Vandermeer, J., Whitbread, A., 2012. Global food security, biodiversity conservation and the future of agricultural intensification. Biol. Conserv. 151, 53-59. https://doi.org/10.1016/j.biocon.2012.01.068

Turbé, A., De Toni, A., Lavelle, P., Benito, P., Lavelle, P., Ruiz, N., Van der Putten, W.H., Mudgal, S., 2010. Soil biodiversity: functions, threats and tools for policy makers: final report. Bio Intelligence Service, IRD, and NIOO, Report for European Commission (DG Environment), Paris.

Turnbull, L.A., Levine, J.M., Loreau, M., Hector, A., 2013. Coexistence, niches and biodiversity effects on ecosystem functioning. Ecol. Lett. 16, 116-127. https://doi.org/10.1111/ele.12056

Williams, A.P., Funk, C., 2011. A westward extension of the warm pool leads to a westward extension of the Walker circulation, drying eastern Africa. Clim. Dyn. 37, 2417-2435. https://doi.org/10.1007/s00382-010-0984-y 


\section{Appendix A: Agricultural production in the different states of nature}

We recall the following relations:

$$
X_{t}=\left\{\begin{array}{c}
E T_{t} \text { if } E T_{t} \leq V_{t-1}+\tilde{\pi}_{t} \\
V_{t-1}+\tilde{\pi}_{t} \text { if else }
\end{array}\right.
$$

The equation above describes how the plant takes water from the soil. If the available water is higher than ET, the plant takes ET. If it is lower than ET, the plant takes what is available.

$$
V_{t}=\frac{V_{t-1}+\tilde{\pi}_{t}-X_{t}}{(1+\beta)}
$$

The equation above gives the quantity of water that remains in the soil after the plant has taken its need. It is assumed that the initial quantity of water before any rainfall is 0 . The following table is built based on the 2 previous equations.

\begin{tabular}{|c|c|c|c|c|c|}
\hline $\begin{array}{c}\text { States of } \\
\text { nature, } \\
S N\end{array}$ & $\begin{array}{l}\text { Rainfall } \\
\text { Period } 1\end{array}$ & $\begin{array}{l}\text { Rainfall } \\
\text { Period } 2\end{array}$ & $\begin{array}{l}\text { Plant uptake } X_{1} \\
\text { Period } 1\end{array}$ & $\begin{array}{l}\text { Water remaining in the soil } \\
\text { between the } 2 \text { periods }\end{array}$ & $\begin{array}{l}\text { Plant uptake } X_{2} \\
\text { Period } 2\end{array}$ \\
\hline 1 & $\pi_{l}$ & $\pi_{l}$ & $\pi_{l}$ & 0 & $\pi_{l}$ \\
\hline 2 & $\pi_{l}$ & $\pi_{h}$ & $\pi_{l}$ & 0 & $E T=\alpha \pi_{l}$ \\
\hline 3 & $\pi_{h}$ & $\pi_{h}$ & $E T=\alpha \pi_{l}$ & $\frac{\gamma-\alpha}{1+\beta} \pi_{l}$ & $E T=\alpha \pi_{l}$ \\
\hline 4 & $\pi_{h}$ & $\pi_{l}$ & $E T=\alpha \pi_{l}$ & $\frac{\gamma-\alpha}{1+\beta} \pi_{l}$ & $\left(1+\frac{\gamma-\alpha}{1+\beta}\right) \pi_{l}$ \\
\hline
\end{tabular}

Table A 1: Table showing the calculation steps of the quantity of water used by plants at each period. 


\section{Appendix B 1: Assumptions and Values used for numeric simulations}

Table B 1: Calibration of the parameters of the bioeconomic model

\begin{tabular}{cll} 
Parameters & Description & Values \\
\hline$\pi_{h}$ & high level of rainfall & 75.85 \\
$\pi_{l}$ & low level of rainfall & 37 \\
$\varphi_{l}$ & probability low level of rainfall & 0.1 to 0.9 \\
$\varphi_{h}$ & probability high level of rainfall & 0.1 to 0.9 \\
$\gamma$ & ratio between the upper and lower level of rainfall & 2.05 \\
$L$ & proportionality coefficient & 37 \\
$I_{b}$ & the stock of soil biodiversity & $2.1 \times 10^{-7}$ to $5.03 \times 10^{-6}$ \\
$\mu$ & rate of change of soil biodiversity & 0.5 \\
$S_{c}$ & soil's water storage capacity & 0.017 to 0.083 \\
$k$ & intrinsic properties of the soil & 1 \\
$E T$ & evapotranspiration & 40.7 \\
$\alpha$ & plant demand coefficient for water & 1.1 \\
$\lambda$ & coefficient of risk aversion & 0 to 0.5 \\
$p$ & crop price & 1 \\
\hline
\end{tabular}

Functional form for $F$ is $F\left(X_{1}, X_{2}\right)=435.56\left(X_{1}+X_{2}+24\right)^{0.5}$ 